\title{
Otimização das condições de ensaio in vivo da enzima redutase do nitrato em Cucurbitáceas
}

\author{
Biank Amorim RODRIGUES ${ }^{1}$, Alessandro Carlos MESQUITA ${ }^{1 *}$ \\ ${ }^{1}$ Departamento de Tecnologia e Ciências Sociais, Universidade do Estado da Bahia, Juazeiro, BA, Brasil. \\ *E-mail: alessandro.mesq@yahoo.com.br \\ (Orcid: 0000-0002-9754-1676; 0000-0003-1892-2997)
}

\begin{abstract}
Recebido em 01/06/2020; Aceito em 18/01/2021; Publicado em 10/02/2021.
RESUMO: As cucurbitáceas abrangem espécies de importância para o Nordeste brasileiro, dentre elas o melão, a melancia e o pepino são as que possuem maior expressividade de cultivo. O sistema de produção dessas hortaliças requer a presença de nitrogênio, que, sendo que a redução do nitrato por meio da atividade da redutase do nitrato no citosol da célula é uma parte importante do processo de incorporação do $\mathrm{N}$ em aminoácidos. Contudo, as metodologias utilizadas são diversas e aplicadas em diversas culturas de forma geral, havendo a necessidade de uma maior especificidade. O presente trabalho teve como objetivo padronizar as condições mais apropriadas para a determinação da atividade da $\mathrm{RN}$, in vivo, no tecido foliar de melancia, melão e pepino. O experimento foi conduzido em delineamento inteiramente casualizado em fatorial $3 \times 3$, compreendendo três metodologias in vivo e três propostas de infiltração do material vegetal (banho-maria, estufa e a vácuo), com quatro repetições. As plantas foram conduzidas em casa de vegetação e os tecidos foliares completamente expandidos foram coletados, após 20 dias da germinação, para a condução dos métodos enzimáticos e avaliar a atividade da enzima redutase do nitrato (NR). Os resultados obtidos demonstraram que a maior atividade da NR no tecido foliar de melancia e melão foi obtida utilizando a Metodologia 1 submetido ao vácuo, enquanto que para o pepino o melhor ensaio foi o Metodologia 2, quando também submetido ao vácuo.
\end{abstract}

Palavras-chave: nitrogênio; metabolismo; enzimologia.

\section{Optimization of in vivo test conditions of nitrate enzyme reductase in Cucurbitacea}

\begin{abstract}
Cucurbits include species of importance to the Northeast of Brazil, among them melon, watermelon and cucumber are those that have the most expressive cultivation. The production system of these vegetables requires the presence of nitrogen, which, whereas the reduction of nitrate through the activity of nitrate reductase in the cell's cytosol is an important part of the process of incorporating $\mathrm{N}$ into amino acids. However, the methodologies used are diverse and applied in different cultures in general, with the need for greater specificity. The present study aimed to standardize the most appropriate conditions for determining the activity of $\mathrm{RN}$, in vivo, in the leaf tissue of watermelon, melon and cucumber. The experiment was conducted in a completely randomized design in a $3 \times 3$ factorial, comprising three in vivo methodologies and three proposals for infiltration of plant material (water bath, greenhouse and vacuum), with four replications. The plants were conducted in a greenhouse and the fully expanded leaf tissues were collected, after 20 days of germination, to conduct the enzymatic methods and evaluate the activity of the nitrate reductase (NR) enzyme. The results obtained demonstrated that the greatest activity of NR in the watermelon and melon leaf tissue was obtained using Methodology 1 submitted to vacuum, while for cucumber the best test was Methodology 2, when also submitted to vacuum.
\end{abstract}

Keywords: nitrogen; metabolismo; enzimology.

\section{INTRODUÇÃO}

Cucurbitaceae é uma família botânica que se destaca pelo significativo cultivo e comércio, com ocorrência e distribuição em várias regiões do mundo. Possui cerca de 1000 espécies, incluindo inúmeras culturas, como pepino (Cucumis sativus), melancia (Citrullus lanatus), melão (Cucumis melo), (SCHAEFER; RENNER, 2011a,b; RENNER; SCHAEFER, 2016). Segundo Chomicki et al. (2019), 10 espécies são de importância econômica mundial, cultivadas globalmente e são consideradas 'grandes culturas', entre elas, a melancia, pepino e melão.

$\mathrm{Na}$ região Nordeste, principalmente no polo agrícola do Submédio do Vale do São Francisco, tanto o melão como a melancia possuem grande representatividade, uma vez que a respectiva produção destas olerícolas, nesta região, no ano de 2017 , correspondeu a $95,2 \%$ e $28,6 \%$ da produção brasileira (IBGE, 2017).

O sucesso de produtividade está associado, entre outras condições, ao manejo nutricional adequado para cada cultivar, normalmente os nutrientes mais fornecidos nas adubações são nitrogênio, fósforo e potássio e os mais acumulados ao final do ciclo são o potássio, nitrogênio e cálcio. Dessa forma, é importante avaliar a dinâmica de absorção do nitrogênio pela planta de modo a evitar a demasia ou a carência no solo (PÔRTO et al., 2012). 
Assim, o conhecimento do mecanismo de transporte e sinalização de nitratos é uma forma de estratégia para melhorar a eficiência da utilização de nitrogênio, reduzir os custos de insumos agrícolas e aliviar os impactos ambientais (WANG, 2018), sobretudo diante do fato de que muitas vezes menos de $50 \%$ do fertilizante de nitrogênio aplicado às culturas é realmente utilizado pelas mesmas (YANG et al., 2010).

O nitrogênio (N) é o elemento fundamental no metabolismo vegetal e requerido pelas plantas em quantidades maiores do que qualquer outro elemento mineral. Isto porque é constituinte de muitos compostos estáveis, incluindo os inorgânicos, como o gás dinitrogênio $\left(\mathrm{N}_{2}\right)$, sais de amônio $\left(\mathrm{NH}_{4}{ }^{+}\right)$e sais de nitrato $\left(\mathrm{NO}_{3}{ }^{-}\right)$e orgânicos, como proteínas e ácidos nucléicos (BLOOM, 2015). Esse mesmo autor relata que as plantas superiores absorvem $\mathrm{N}$ do solo nas formas de amônio ou nitrato, provenientes, principalmente, da mineralização da matéria orgânica pelos microrganismos, e de uréia, através da aplicação de fertilizantes químicos, ainda assim, sob condições aeróbicas, o nitrato é a forma predominante de nitrogênio no solo.

Nos solos aeróbicos, a principal forma de $\mathrm{N}$ inorgânico é o nitrato. Para muitas plantas, pouco nitrato é absorvido pelas raízes e assimilado pelas mesmas, pois a maior parcela é transportada para a parte aérea, onde é primeiro reduzido a nitrito pela Nitrato Redutase, no citoplasma. Assim, estudos que avaliam a absorção e assimilação de $\mathrm{N}$ na forma nítrica, necessariamente avaliam a atividade dessa enzima (XU; MILLER, 2012).

Dentro da célula, o nitrato é primeiramente reduzido a nitrito pela enzima citossólica Redutase do Nitrato (RN), sendo este o passo limitante na via de assimilação. Em seguida, o nitrito gerado é transportado para o cloroplasto por sistemas específicos, onde a enzima Nitrito Redutase (NiR) catalisará o processo de redução do nitrito a amônio, o qual finalmente será incorporado às cadeias carbônicas mediante a geração de glutamato através do ciclo da Glutamina Sintetase (GS)/Glutamato Sintetase (GOGAT) (SANZ-LUQUE et al., 2015). Em resumo, a assimilação de nitrato ocorre por uma via linear simples, englobando dois transportes (de nitrato e de nitrito) e duas etapas de redução (envolvendo NR e NiR) (CHAMIZO-AMPUDIA et al., 2017).

Além do seu papel como nutriente, o nitrato também é um sinal importante para respostas moleculares, metabólicas e fisiológicas a níveis locais e sistêmicos da planta, bem como fornece sinais que modulam a expressão dos genes de assimilação de nitrato e regulam o desenvolvimento das raízes laterais (KRAPP et al., 2014), aliviam a dormência de sementes (FORDE e WALCH-LIU, 2009) e modulam a morfogênese foliar, além de atuar regulando mecanismos transcricional, traducional e pós-traducional (MAZID et al., 2012).

Os ensaios para determinar a atividade enzimática da NR podem ser in vivo ou in vitro. No primeiro método, a enzima não é extraída do interior da célula, pois sua membrana é artificialmente permeabilizada para permitir a liberação dos produtos da reação. Devido à simplicidade, Mulder et al. (1959) foram responsáveis por publicar, pela primeira vez, o ensaio in vivo da NR em discos foliares, e desde então, tem sido amplamente utilizado com várias modificações. Em 1971, Klepper et al., Jaworski e Hageman \& Reed propuseram algumas condições ótimas dos fatores para a atividade da redutase do nitrato in vivo, principalmente em plantas de milho, soja, tabaco e tomate. Mais tarde, Radin (1973) descreveu os efeitos de várias condições de incubação na atividade da NR em folhas de algodão, seguido pelos ensaios de Cataldo et al. (1975), utilizando plantas de milho e aveia, demonstrou um método rápido, livre de interferências de outros íons presentes nos tecidos vegetais e adequado para amostras com ampla gama de concentrações de nitrato.

São poucas as informações na literatura sobre a atividade da Nitrato Redutase em Cucurbitáceas, e a metodologia utilizada para os ensaios in vivo baseia-se em técnicas desenvolvidas para outras espécies. Os trabalhos envolvidos, geralmente, avaliam a resposta fisiológica de cultivares em função da aplicação de fungicidas (MACEDO, 2017; SIRTOLI et al., 2011), bem como a influência do déficit hídrico e adubação nitrogenada (CAMPOS et al., 2017) e o comportamento frente à utilização de biofertilizantes.

Portanto, o estabelecimento de condições apropriadas para a determinação enzimática da NR é necessário, posto que cada espécie possui particularidades anatômicas e fisiológicas. Na literatura é possível encontrar metodologias já aprimoradas para plantas de cana-de-açúcar (SANTOS et al., 2014; BARBOSA et al., 2016) e Camapu (Physalis angulata L.) (TANAN, 2019). Contudo, para cucurbitáceas ainda são utilizados os protocolos originais, desenvolvidos por Klepper et al. (1971), Jaworski (1971) e Cataldo et al. (1975) para plantas de tomate, soja, milho e aveia.

Nessa perspectiva, este trabalho teve como objetivo padronizar e caracterizar um protocolo laboratorial com as melhores condições para determinação in vivo da atividade enzimática da Redutase do Nitrato, no tecido foliar de algumas cucurbitáceas.

\section{MATERIAL E MÉTODOS}

As plantas foram conduzidas em casa de vegetação no Departamento de Tecnologia e Ciências Sociais - DTCS, Campus III, da Universidade do Estado da Bahia, na cidade de Juazeiro-BA. Sementes de melancia cv. Crimson Sweet, melão cv. Gladial e pepino cv. Pepino Verde Comprido foram colocadas para germinar em sacos de polietileno contendo substrato comercial. Aos 7 e 14 dias após a germinação foi feita apenas aplicação dos nutrientes Fósforo e Potássio, em proporções adequadas de acordo com a necessidade de cada cultura, para o auxílio no desenvolvimento inicial, após a emergência das mudas, até o surgimento da primeira folha definitiva.

As plantas foram mantidas em casa de vegetação, com irrigações diárias, e, para os diferentes métodos, aos 20 dias após a germinação, foram selecionadas aquelas cuja folha definitiva encontrava-se completamente expandida. Para cada uma das culturas realizou-se um experimento independente. Em cada experimento, adotou-se o delineamento experimental inteiramente casualizado, em fatorial $3 \times 3$, compreendendo três métodos in vivo, três propostas de infiltração do material vegetal (banho-maria, estufa e a vácuo), com quatro repetições.

\subsection{Ensaios in vivo}

Para a estimativa da atividade da Nitrato Redutase in vivo, os três métodos descritos abaixo tiveram como base as metodologias propostas por Jaworski (1971) e Meguro; Magalhães (1982) com algumas modificações (Tabela 1) 


\section{Rodrigues; Mesquita}

visando otimizar a técnica para folhas da melancia, melão e pepino, descritas a seguir:

Método 1: Fragmentos de 0,1 g de tecidos foliares foram incubados em frascos protegidos da luz, contendo $5 \mathrm{~mL}$ de solução tampão fosfato (K2HPO4 + $\left.\mathrm{KH}_{2} \mathrm{PO} 4,0,1 \mathrm{~mol} \mathrm{~L}^{-1}\right)$, $\mathrm{pH} 7.0$, adicionado de $1 \mathrm{~mL}$ de nitrato de potássio (KNO3 $\left.0,28 \mathrm{~mol} \mathrm{~L}^{-1}\right)$ e $1 \mathrm{~mL}$ de $\mathrm{n}$ - propanol $(1 \% \mathrm{v} / \mathrm{v})$. Ao final do processo, após a infiltração, foi transferido $1 \mathrm{~mL}$ do meio de reação para tubos de ensaio contendo: $1 \mathrm{~mL}$ de $\mathrm{n}$-naftil etileno diamina $0,01 \%(\mathrm{~m} / \mathrm{v})$ e $1 \mathrm{~mL}$ de sulfanilamida $0,1 \%$ em $\mathrm{HCl} \mathrm{3,0} \mathrm{mol} \mathrm{L-1}$, seguida da leitura da absorbância no espectrofotômetro.

Método 2: Fragmentos de 0,5 $\mathrm{g}$ de tecidos foliares foram colocados em frascos protegidos da luz, contendo $8 \mathrm{~mL}$ de solução tampão fosfato $\left(\mathrm{K}_{2} \mathrm{HPO} 4+\mathrm{KH}_{2} \mathrm{PO} 4,0,3 \mathrm{~mol} \mathrm{~L}^{-1}\right)$, $\mathrm{pH} 7.5$, adicionado de $1 \mathrm{~mL}$ de nitrato de potássio (KNO3 0,3 mol L-1) e $1 \mathrm{~mL}$ de $\mathrm{n}$ - propanol $(1 \% \mathrm{v} / \mathrm{v})$. Após infiltração, $5 \mathrm{~mL}$ desse meio foi transferido para uma cubeta de vidro e acrescentados $0,5 \mathrm{~mL}$ de solução de sulfanilamida $10 \mathrm{~g} \mathrm{~L}^{-1}$ em HCl 3,0 mol L-1 e 0,5 de n-naftil etileno diamina $0,2 \mathrm{~g} \mathrm{~L}^{-1}$. A mistura foi homogeneizada, e, após 20 minutos o volume foi completado a $4 \mathrm{~mL}$ com água deionizada e a absorbância medida em espectrofotômetro.
Método 3: Fragmentos de 0,2 $\mathrm{g}$ de tecidos foliares foram colocados em frascos protegidos da luz, contendo $6 \mathrm{~mL}$ de tampão fosfato (K2HPO4 + KH2PO4, 0,2 mol L-1), $\mathrm{pH} 7.3$, adicionado de $1 \mathrm{~mL}$ de nitrato de potássio (KNO3 0,05 mol $\left.\mathrm{L}^{-1}\right)$ e $1 \mathrm{~mL}$ de n-propanol (3\% v/v). Para se determinar a quantidade de nitrito formada pela reação, após infiltração, foram retiradas alíquotas de $0,5 \mathrm{~mL}$ do meio de incubação, adicionada de $1 \mathrm{~mL}$ de sulfanilamida $1 \%$ em $\mathrm{HCl} 1,5 \mathrm{~N}, 1 \mathrm{~mL}$ de N-2-naftil-etileno $0,02 \%$ e $1,5 \mathrm{~mL}$ de água destilada e levadas para leitura em espectrofotômetro.

A concentração de nitrito produzida foi determinada em espectrofotômetro a $540 \mathrm{~nm}$ e a atividade da RN estimada em $\mu \mathrm{mol}$ de nitrito liberado por $1 \mathrm{~g}$ de tecido fresco por hora de incubação ( $\mu \mathrm{mol} \mathrm{NO} 2 \mathrm{~g}^{-1} \mathrm{mf} \mathrm{h}^{-1}$ ) e calculada com base em equação linear obtida a partir do preparo prévio na curvapadrão.

O branco do espectrofotômetro foi feito seguindo o mesmo procedimento para as amostras, no entanto o tampão de extração foi substituído pelo mesmo tampão sem adição de KNO3. Para melhor compreensão, segue abaixo na Tabela 1, um resumo contendo as principais diferenças entre os métodos.

Tabela 1. Caracterização dos diferentes métodos para otimização do método e determinação da Nitrato Redutase em tecidos foliares de melancia, pepino e melão.

Table 1. Characterization of the different tests for optimization of the method and determination of Nitrate Reductase in leaf tissues of watermelon, cucumber and melon.

\begin{tabular}{ccccccc}
\hline & Tecido foliar $(\mathrm{g})$ & $\mathrm{KH}_{2} \mathrm{PO}\left(\mathrm{mol} \mathrm{L}^{-1}\right)$ & $\mathrm{pH} / \mathrm{HH}_{2} \mathrm{PO}_{4}$ & $\mathrm{KNO}_{3}\left(\mathrm{~mol} \mathrm{~L}^{-1}\right)$ & Propanol $(\%)$ & $\mathrm{VF}(\mathrm{mL})$ \\
\hline M 1 & 0,1 & 0,1 & 7.0 & 0,28 & 1 & 7 \\
M 2 & 0,5 & 0,2 & 7.5 & 0,3 & 1 & 10 \\
M 3 & 0,2 & 0,3 & 7.3 & 0,05 & 3 & 8 \\
\hline
\end{tabular}

Para todos os ensaios, após a incubação do tecido foliar em tampão, foram realizadas as três formas de infiltração: a) banho-maria sem o vácuo a $35{ }^{\circ} \mathrm{C}$ por 60 minutos, na ausência de luz; b) estufa a $35^{\circ} \mathrm{C}$ por 60 min na ausência de luz; c) bomba de vácuo por duas vezes, 1 minuto cada, utilizando dessecador ligado a bomba pressurizadora e depois mantidos na ausência de luz em banho-maria a $32^{\circ} \mathrm{C}$, por 60 minutos; d) após o processo de incubação, as alíquotas foram retiradas e as análises enzimáticas realizadas como descrito anteriormente, especifico para cada método aplicado; e) Os dados obtidos foram submetidos à análise de variância, com comparação entre as médias feitas pelo teste de Tukey em nível de $5 \%$ de probabilidade de erro, através do software estatístico SISVAR versão 5.6 beta (FERREIRA, 2011).

\section{RESULTADOS}

Os resultados obtidos com a análise de variância demonstraram interação significativa para a interação entre os métodos e os tipos de infiltração testados para as três espécies analisadas, sendo que as Figuras foram compostas pelo desdobramento da interação para cada fator avaliado.

Para a melancia (Figura 1A), pode-se verificar que avaliando os métodos enzimáticos aplicados, o Método 1 foi superior aos demais quando usado a bomba de vácuo, representando um ganho de $38 \%$ e $220 \%$ em relação ao método 2 e 3 respectivamente. $\mathrm{Na}$ condução em condição de estufa, os Métodos 1 e 2 foram similares e superiores ao Método 3, que apresentou uma perda em torno de 108\% quando comparado aos demais. Já quando observamos o ensaio conduzido em banho maria, o melhor resultado foi obtido quando conduzido no Método 3, com valores na atividade enzimática superiores em 28\% e 700\% quando comparado ao Método 1 e 2, respectivamente.

Quando avaliamos os tipos de incubação dentro de cada método (Figura 1B), o melhor resultado foi obtido no Método 1 quando utilizado a bomba de vácuo como meio de infiltração; o Método 2 não apresentou diferença entre estufa e bomba de vácuo; e que no Método 3, o melhor resultado foi obtido quando conduzido em banho-maria.

Deve-se ressaltar que como demonstrado na Tabela 1, o Método 1 foi aquele com menor quantidade de tecido vegetal utilizado $(0,1 \mathrm{~g} \mathrm{MF})$, menor quantidade de fosfato de potássio $\left(0,1 \mathrm{~mol} \mathrm{~L}^{-1}\right)$ e $\mathrm{pH}$ em 7,0. Em função disso, ocorre também uma redução no gasto destes reagentes.

Para a cultura do melão, observa-se na Figura 2A uma superioridade na atividade da enzima Nitrato Redutase quando utilizado o Método 1, independentemente do meio de infiltração aplicado, sendo que isso fica evidenciado na Figura 2B. Contudo, é importante destacar que os maiores valores médios observados foram obtidos quando se utilizou o Método 1 e a incubação do meio em bomba de vácuo, com ganho em superioridade da atividade enzimática em torno de $98 \%$ e de $668 \%$ em relação ao Método 2 e 3 , respectivamente.

O comportamento similar da atividade da NR para folhas de melancia e melão submetidos às mesmas condições de ensaio pode ser explicado devido às semelhanças fisiológicas para o fracionamento constante da redução do nitrato, além da composição do meio de incubação ter favorecido esta 
resposta, uma vez que a concentração de $\mathrm{KNO} 30,28 \mathrm{~mol} \mathrm{~L}$ 1 garantiu a situação de saturação da enzima pelo substrato, para se desenvolver todo o tempo de incubação em situação de velocidade máxima da enzima.

Com relação aos valores obtidos da enzima Nitrato Redutase para a cultura do pepino, ficou determinado na Figura 3A que o Método 1, diferentemente do relatado para a cultura da melancia e melão, não sobressaiu sobre os demais. Pode-se observar que o Método 2 conduzido na estufa e na bomba de vácuo apresentou os valores médios superiores aos demais tratamentos, com maior atividade expressa quando utilizado a bomba de vácuo, representando um ganho na atividade da enzima de $250 \%$ e $455 \%$ quando comparado ao Método 1 e 3, respectivamente. O Método 3 conduzido no banho maria foi superior aos demais métodos. Esse comportamento fica comprovado quando analisamos a Figura 3B.
Ao se obter os valores médios levando em consideração as culturas avaliadas (Figura 4), podemos melhor visualizar os resultados demonstrados nas Figuras anteriores.

Verifica-se que para a cultura da melancieira e do meloeiro (Figura 4A), o método 1 apresenta os melhores resultados, e que para o pepino, houve uma superioridade do método 2, contudo, apresentando valores inferiores aos obtidos nas outras culturas. Ao observarmos os resultados em função do meio de incubação (Figura 4B), pode-se evidenciar uma superioridade quando do uso da estufa de circulação fechada em comparação aos demais métodos, para a cultura da melancieira e meloeiro. Já para a cultura do pepino, observamos uma padronização nos resultados e como citado anteriormente, ressalta-se uma inferioridade na atividade da enzima em comparação com as demais culturas.

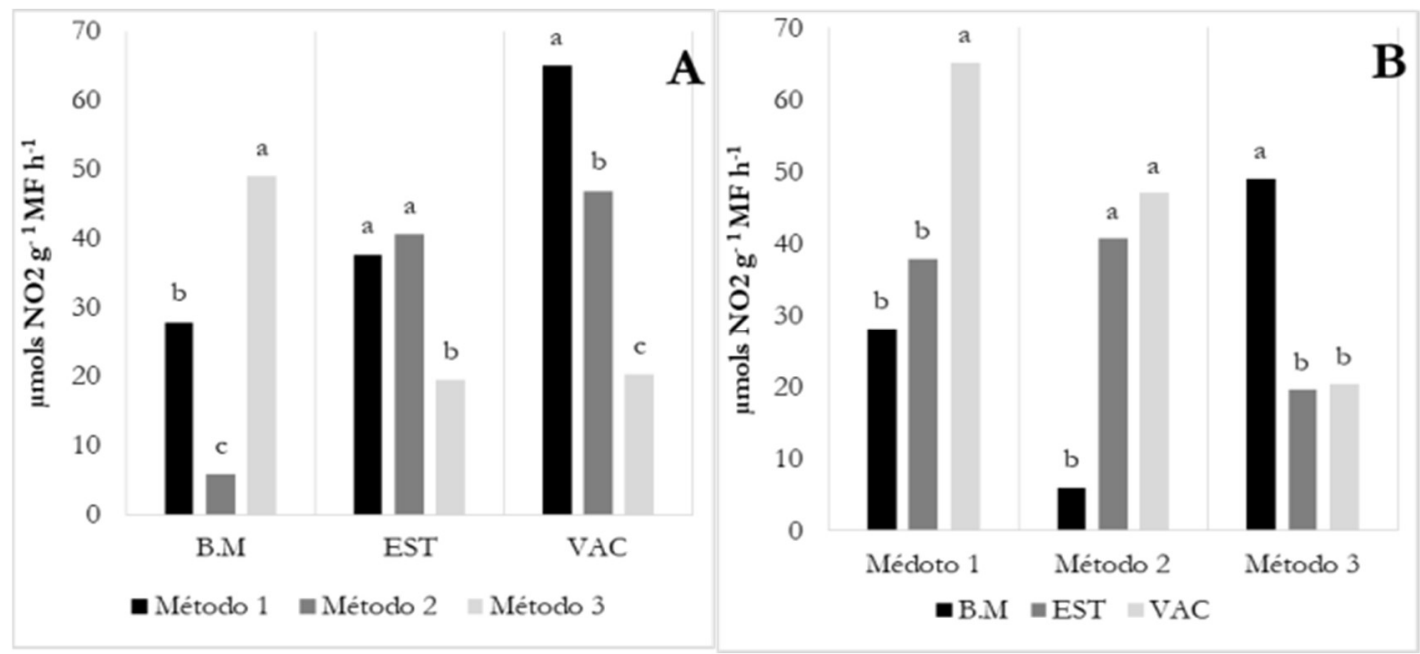

As médias seguidas da mesma letra não diferem entre si pelo teste de Tukey, ao nivel de $5 \%$ de probabilidade.

Figura 1. Comportamento da atividade da Nitrato Redutase (NR) em tecidos foliares de melancia (Citrullus lanatus) quando desdobrado os ensaios dentro de cada condição de infiltração (A); e as condições de infiltração dentro de cada método (B). B.M - banho-maria; ESTestufa; VAC - vácuo.

Figure 1. Behavior of Nitrate Reductase (NR) activity in watermelon leaf tissues (Citrullus lanatus) when the tests were deployed within each infiltration condition (A); and the infiltration conditions within each method (B). B.M - water bath; EST- drying oven; VAC - vacuum.

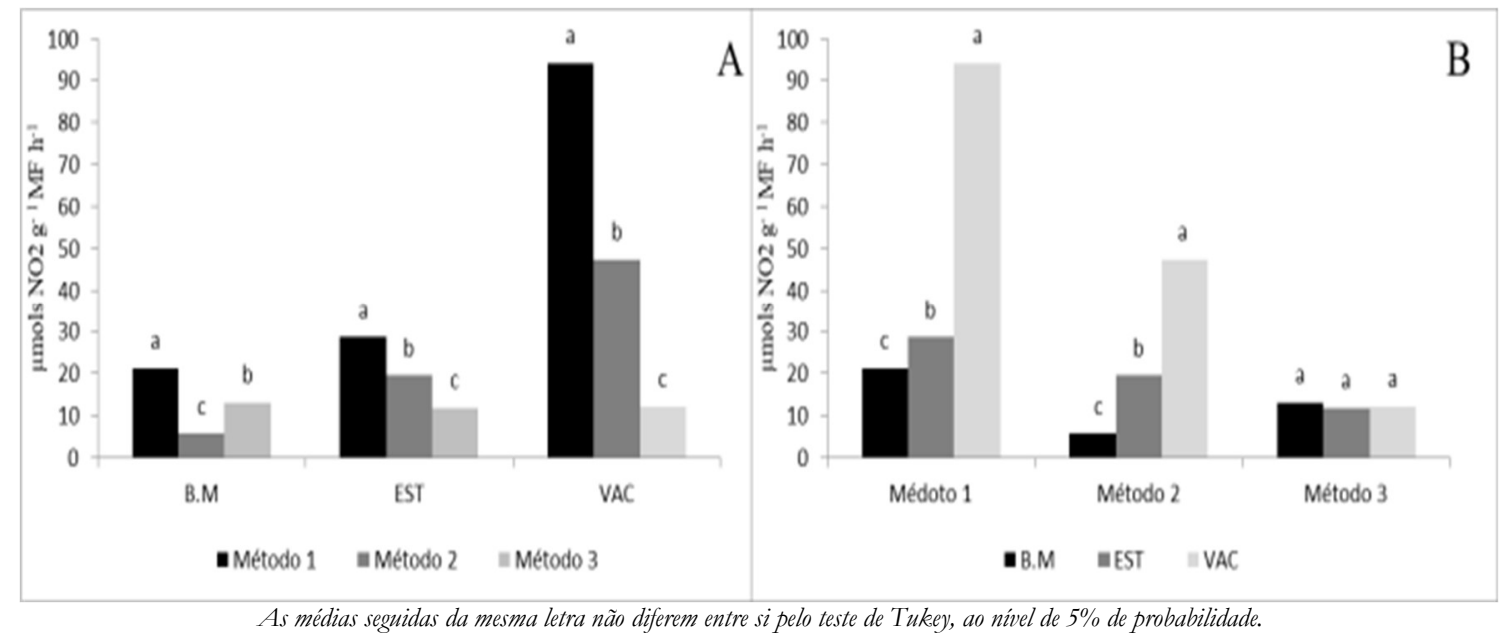

Figura 2. Comportamento da atividade da Nitrato Redutase (NR) em tecidos foliares de melão (Cucumis melo) quando desdobrado os ensaios dentro de cada condição de infiltração (A); e as condições de infiltração dentro de cada método (B). B.M - banho-maria; EST- estufa; VAC - vácuo.

Figure 2. Behavior of the activity of Nitrate Reductase (NR) in leaf tissues of melon (Cucumis melo) when deployed the tests within each infiltration condition (A); and the infiltration conditions within each method (B). B.M - water bath; EST- drying oven; VAC - vacuum. 


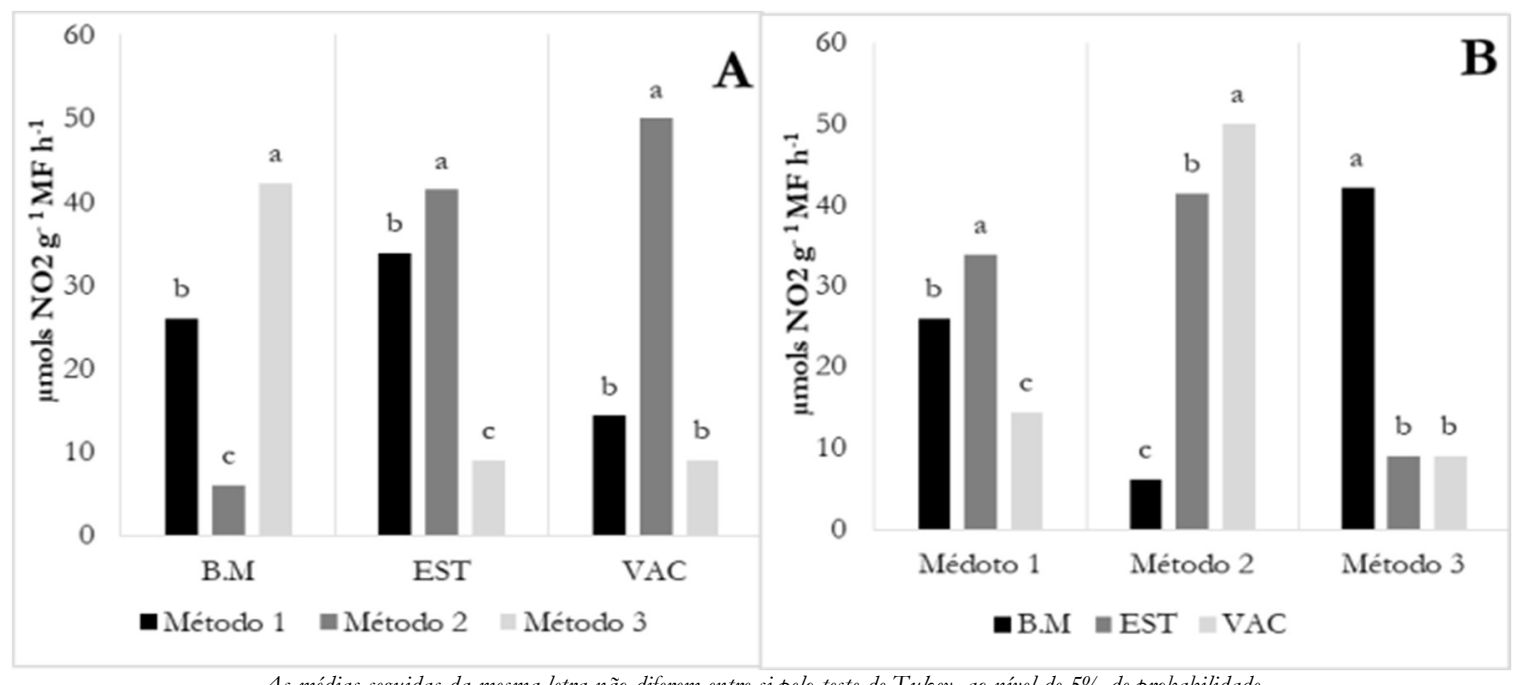

As médias seguidas da mesma letra não diferem entre si pelo teste de Tukey, ao nivel de $5 \%$ de probabilidade.

Figura 3. Comportamento da atividade da Nitrato Redutase (NR) em tecidos foliares de pepino (Cucumis sativus) quando desdobrado os ensaios dentro de cada condição de infiltração (A); e as condições de infiltração dentro de cada método (B). B.M - banho-maria; ESTestufa; VAC - vácuo.

Figure 3. Behavior of Nitrate Reductase (NR) activity in leaf tissues of cucumber (Cucumis sativus) when the tests were deployed within each infiltration condition (A); and the infiltration conditions within each method (B). B.M - water bath; EST- drying oven; VAC - vacuum.
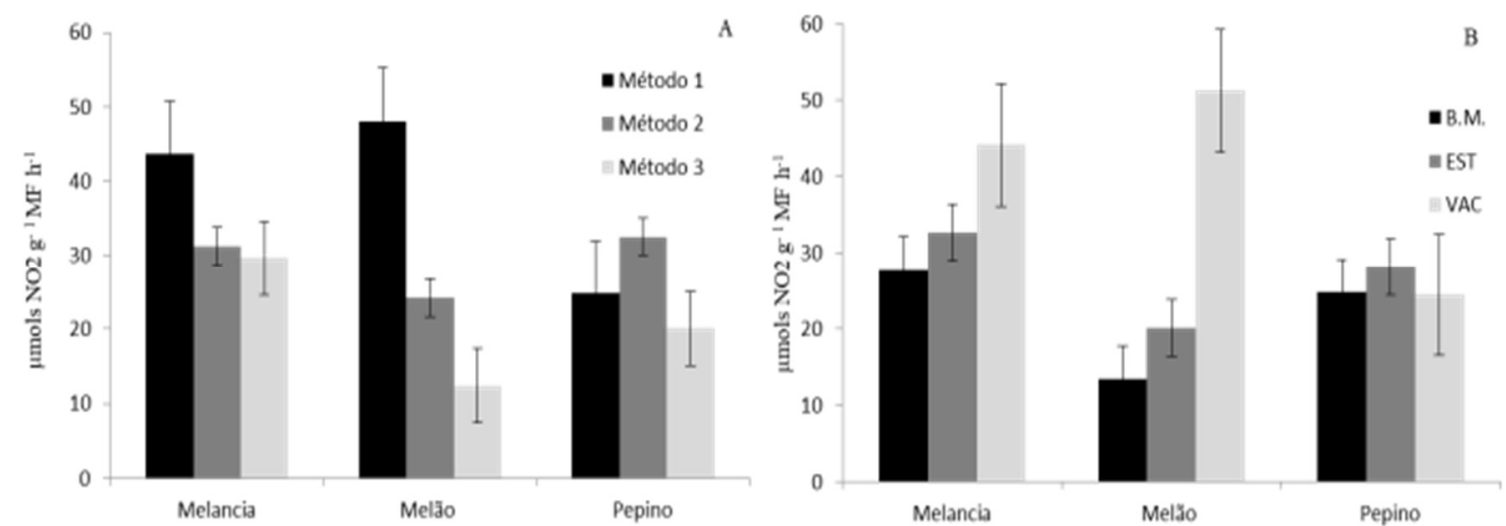

Figura 4. Comportamento da atividade da Nitrato Redutase (NR) em tecidos foliares de melancia (Citrullus lanatus); melão (Cucumis melo) e pepino (Cucumis sativus) em função do método avaliado (A); e nas condições de infiltração (B).

Figure 4. Behavior of Nitrate Reductase (NR) activity in watermelon leaf tissues (Citrullus lanatus); melon (Cucumis melo) and cucumber (Cucumis sativus) according to the evaluated method (A); and infiltration conditions (B).

\section{DISCUSSÃO}

Nas três espécies de estudo, nota-se que os tratamentos utilizando o banho-maria como meio de infiltração demonstrou reduzidas atividades enzimáticas, principalmente associado ao Método 2, este fato sugere pouca eficácia deste método em romper a parede celular, para que o nitrato contido no meio de incubação entre no interior das células, e que o nitrito produzido seja distribuído para o meio de incubação e detectado. É importante destacar que o banho maria utilizado não tinha a opção de agitação, fato este que pode ter influenciado. Contudo, tal evento pode ter sido compensado, no Método 3, em que a concentração do solvente n-propanol (3\%) utilizada foi maior, ao mesmo tempo que a concentração de $\mathrm{KNO} 3$ foi a menor $(0,05 \mathrm{~mol}$ $\left.\mathrm{L}^{-1}\right)$.

A função do solvente, além de diminuir a tensão superficial, é proporcionar o aumentoda permeabilidade celular ao nitrato e nitrito, dessa forma auxilia a passagem do nitrato oriundo do meio de incubação, do vacúolo para o citoplasma, local onde ocorre a redução pela NR (JAMUR; OLIVER, 2010).
Assim como o emprego do banho-maria expressou menores atividade da NR, a submissão dos tratamentos ao vácuo sobressaiu-se, apresentando maiores atividades enzimáticas. Tal ocorrido contraria os resultados obtidos por Santos et al. (2014) em folhas de cana de açúcar, no qual não houve diferença significativa na atividade da NR dos tratamentos com vácuo e no tratamento sem vácuo. Entretanto, Tanan (2019), em seu trabalho com folhas de camapu observou os maiores valores da atividade da NR com a submissão do meio de incubação ao vácuo.

Macedo (2012) em seu trabalho com melão e Sirtoli et al. (2011) com pepineiro, encontraram valores para a atividade enzimática da NR, próximos a 33,5 e 37,6 $\mu$ mols $\mathrm{NO}_{2} \mathrm{~g}$ ${ }^{1} \mathrm{mfh}^{-1}$, respectivamente. $\mathrm{Na}$ metodologia adotada $\mathrm{em}$ ambos experimentos, as amostras também foram submetidas ao vácuo, em meio de incubação com concentrações de $\mathrm{KH} 2 \mathrm{PO} 4$ 0,05 mol L-1 e KNO3 0,1 mol L-1, sem adição de solvente, para o primeiro; enquanto que o outro utilizou $\mathrm{KH}_{2} \mathrm{PO} 40,1 \mathrm{~mol} \mathrm{~L}^{-1}$ contendo $0,0005 \mathrm{~mol}$ $\mathrm{L}^{-1}$ de $\mathrm{KNO}_{3}$ e $1 \%$ de propanol. Tais valores da aNR estão 
dentro da faixa de variação encontrado no presente trabalho cuja aNR variou de 12,24 até 94,15 $\mu$ mols $\mathrm{NO}_{2} \mathrm{~g}^{-1} \mathrm{mf} \mathrm{h}^{-1}$, para o melão e 9,01 até 50,05 $\mu$ mols $\mathrm{NO}_{2} \mathrm{~g}^{-1} \mathrm{mf} \mathrm{h}^{-1}$, para o pepino. Isto sugere que as concentrações de tampão $\mathrm{KH}_{2} \mathrm{PO} 4, \mathrm{KNO} 3$, e a utilização de solvente também sejam fatores que induzem maiores ou menores atividades enzimáticas.

\section{CONCLUSÕES}

A maior atividade da Nitrato Redutase no tecido foliar de melancia e melão foi obtida utilizando- se o meio de incubação contendo $0,1 \mathrm{~g}$ de tecido foliar, tampão fosfato 0,1 mol L-1 $\mathrm{pH} 7.0$, KNO3 $0,28 \mathrm{~mol} \mathrm{~L}^{-1}$, e n-propanol $1 \%$ (Método 1), submetidos duas vezes, durante 1 minuto, à vácuo.

A atividade da Nitrato Redutase foi melhor observada no tecido foliar do pepino utilizando-se o meio de incubação contendo $0,5 \mathrm{~g}$ de tecido foliar, tampão fosfato $0,2 \mathrm{~mol} \mathrm{~L}^{-1}$, pH 7.5, KNO3 0,3 mol L-1, e n-propanol 1\% (Método 2), também submetido ao vácuo.

\section{REFERÊNCIAS}

BARBOSA, J. de A.; GUEDES, V. H. F.; MOURA, M. J. A.; COSTA, L. G. A. F. Amostragem para determinação da atividade da redutase do nitrato em folhas de cana- deaçúcar. In: Congresso Internacional das Ciências Agrárias, 1., 2016. Anais [...]. Recife: 2016. DOI: $10.31692 / 2526-$

7701.ICOINTERPDVAGRO.2016.00004

BLOOM, A. J. The increasing importance of distinguishing among plant nitrogen sources. Current Opinion in Plant Biology, v. 25, p. 10-16, 2015. DOI: 10.1016/j.pbi.2015.03.002

CAMPOS, L. D. A.; FERREIRA, K. M.; ROCHA, D. N. S.; MESQUITA, A. C.; SIMOES, W. L. Influência do déficit hídrico controlado e da adubação nitrogenada nas características bioquímicas do meloeiro. In: Embrapa Semiárido-Artigo em anais de congresso (ALICE). In: Congresso Brasileiro de Agrometeorologia, Juazeiro-BA, 2017.

CATALDO, D. A.; MAROON, M.; SCHARADER, L. E.; YOUNGS, V. L.; Rapid colorimetrie determination of nitrate in plant tissue by nitration of salicylic acid. Communications in Soil Science and Plant Analysis, v. 6 , n. 1, p. 71-80, 1975. DOI: $10.1080 / 00103627509366547$

CENSO AGROPECUÁRIO 2017. In: IBGE. Sidra: Sistema IBGE de Recuperação Automática. Disponível em:<https://sidra.ibge.gov.br/home/lspa/brasil> Acesso em: 20 mai 2019.

CHAMIZO-AMPUDIA, A.; SANZ-LUQUE, E.; LLAMAS, A.;GALVAN, A.;FERNANDEZ, E. Nitrate Reductase Regulates Plant Nitric Oxide Homeostasis. Trends in Plant Science, v. 22, n. 2, p. 163-174, 2017. DOI: 10.1016/j.tplants.2016.12.001

CHOMICKI, G.; SCHAEFER, H.; RENNER, S.S. Origin and domestication of Cucurbitaceae crops: insights from phylogenies, genomics and archaeology. New Phytologist, v. 226, p. 1240-1255, 2020. DOI: https://doi.org/10.1111/nph.16015

FERREIRA， D. F. Programa de análises estatísticas (statistical analysis sotware) e planejamento de experimentos - SISVAR 5.6 (Build 67). Lavras: DEX/UFLA, 2011.

FORDE, B. G.; WALCH-LIU, P. Nitrate and glutamate as environmental cues for behavioural responses in plant roots. Plant, Cell \& Environment, v. 32, n. 6, p. 682693, 2009. DOI: 10.1111/j.1365-3040.2008.01927.x

JAMUR, M. C.; OLIVER, C. Permeabilization of cell membranes. In: OLIVER, C.; JAMUR, M.C. (Ed.). Immunocytochemical methods and protocols. 3rd ed. Totowa: Humana Press, 2010. v. 588, p. 63-66. DOI: 10.1007/978-1-59745-324-0_9.

JAWORSKI, E. G. Nitrate reductase assay in intact plant tissues. Biochemical and Biophysical Research Communications, London, v. 43, p. 1274-1279, 1971.

KLEPPER, L.; FLESHER, D. F.; HAGEMAN, R. H. Generation of reduced nicotinamide-adenine-dinucleotide for nitrate reduction in green leaves. Plant Physiology, v. 48, p. 580-590, 1971.

KRAPP, A.; DAVID, L. C.; CHARDIN, C.; GIRIN, T.; MARMAGNE, A.; LEPRINCE, A.; CHAILLOU, S.; MÉRY, S.; MEYER, C.;VEDELE, F. D. Nitrate transport and signalling in Arabidopsis. Journal of Experimental Botany, v. 65, n. 3, p. 789-798, 2014. DOI: $10.1093 / \mathrm{jxb} / \mathrm{eru001}$

MACEDO, A. C.; AMARO, A. C. E.; RAMOS, A. R. P.; ONO, E. O.; RODRIGUES, J. D. Strobilurin and boscalid in the quality of net melon fruits. Semina: Ciências Agrárias, Londrina, v. 38, n. 2, p. 543-550, 2017. DOI: $10.5433 / 1679-0359.2017 v 38 n 2 p 543$

MACEDO, A. C. Efeitos fisiológicos de fungicidas no desenvolvimento de plantas de melão rendilhado, cultivadas em ambiente protegido. 2012. $66 \mathrm{f}$. Dissertação (Mestrado em Horticultura) -Faculdade de Ciências Agronômicas, Universidade Estadual Paulista, Botucatu, 2012.

MAZID, M.; KHAN, T. A.; MOHAMMAD, F. Role of nitrate reductase in nitrogen fixation under photosynthetic regulation. World Journal of Pharmaceutical Research, v. 1, p. 386-414, 2012.

MEGURO, N. E.; MAGALHÃES, A. C. Atividade da Redutase de nitrato em cultivares de café. Pesquisa Agropecuária Brasileira, Brasília, v. 17, p. 249-257, 1982.

MULDER, E. G.; BOXMA, R.; VAN VEEN, W. L. The effect of molybdenum and nitrogen deficiencies on nitrate reduction in plant tissues. Plant and Soil, v. 10, n. 4, p. 335-355, 1959.

PÔRTO, M. L. A.; PUIATTI, M.; FONTES, P. C. R.; CECON, P. R.; ALVES, J. C.; ARRUDA, J. A. Produtividade e acúmulo de nitrato nos frutos de abobrinha em função da adubação nitrogenada. Bragantia, Campinas, v. 71, n. 2, p. 190-195, 2012. http://dx.doi.org/10.1590/S0006-87052012005000020.

RADIN, J. W. In vivo assay of nitrate reductase in cotton leafdiscs. Plant Physiology, v. 51, n. 2, p. 332-336, 1973. Disponível em: http://www.plantphysiol.org/content/51/2/332.full.pd f + html. Acesso em: 13 abr. 2019. doi: 10.1104/pp.51.2.332

RENNER S. S.; SCHAEFER H. Phylogeny and evolution of Cucurbitaceae. In: GRUMET, R.; KATZIR, N.; GARCIA-MAS, J. (Eds). Genetics and genomics of Cucurbitaceae. Cham, Switzerland: Springer 
International, 2016, p.13-23.

SANTOS, C. L. R., CAZETTA, J.O.; SARAN, L.M.;SANCHES, A. Otimização da análise da atividade da redutase do nitrato e sua caracterização em folhas de cana-de-açúcar. Pesquisa Agropecuária Brasileira, Brasília, v. 49, p. 384-94, 2014. DOI: https://doi.org/10.1590/S0100-204X2014000500008.

SANZ-LUQUE, E.; AMPUDIA, A. C.; LLAMAS, A.; GALVAN, A.; FERNÁNDEZ, E. Understanding nitrate assimilation and its regulation in microalgae. Frontiers in Plant Science, v. 6, 2015. doi: 10.3389/fpls.2015.00899

SCHAEFER, H.; RENNER, S. S. Phylogenetic relationships in the order Cucurbitales and a new classification of the gourd family (Cucurbitaceae). Taxon, v. 60, n. 1, p. 122 138, 2011a. DOI: 10.1002/tax.601011

SCHAEFER, H.; RENNER, S. S. Cucurbitaceae. Pp. 112174. In: KUBITZKI, K. (Ed.). Families and Genera of Flowering Plants, v. 10. Berlin: Springer Verlag, 2011b.

SIRTOLI, L. F.; RODRIGUES, J. D.; GOTO, R. Efeito fisiológico do fungicida boscalida na atividade da nitrato redutase e nas características fitotécnias de pepineiro japonês enxertado e não enxertado. Scientia Agraria Paranaensis, v. 10, p. 58-69, 2011.

TANAN, T. T. Absorção, assimilação e transporte de nitrogênio em plantas de physalis angulatal $\mathrm{L}$. Tese (doutorado) -Universidade Estadual de Feira de Santana. Programa de Pós-Graduação em Recursos Genéticos Vegetais, 2019. 123p.

WANG, Y. Y.; CHENG, Y. H.; CHEN, K.; TSAY, Y. F. Nitrate Transport, Signaling, and Use Efficiency. Annual Review of Plant Biology, v. 69, n. 1, p. 85-122, 2018. DOI: 10.1146/annurev-arplant-042817-040056

XU, G.; FAN, X.; MILLER, A. J. Plant Nitrogen Assimilation and Use Efficiency. Annual Review of Plant Biology, v. 63, n. 1, p. 153-182, 2012. DOI: 10.1146/annurev-arplant-042811-105532

YANG, X.; WANG, Y. F.; WEI, M.; YANG, F. J.; SHI, Q. H. Changes of Nitrate Reductase Activity in Cucumber Seedlings in Response to Nitrate Stress.Agricultural Sciences in China, v. 9, n. 2, p. 216-222, 2010. DOI: 10.1016/s1671-2927(09)60086-9 